\title{
Clinicopathological features of young age breast cancer patients in Bali
}

\author{
I Wayan Sudarsa* \\ Surgical Oncology Subdivision Department of Surgery, Faculty of Medicine \\ University of Udayana, Sanglah General Hospital Denpasar Bali
}

DOI: http://dx.doi.org/10.19106/JMedScieSup0048042016014

\section{ABSTRACT}

Breast cancer is a heterogeneous disease with diverse biological characteristics, histopathological types, subtypes, and clinical behavior. Breast cancer in young individuals, albeit rare, is usually unique, more aggressive, and associated with poorer prognosis. The combination of young age and advanced stage of breast cancer would make this particular breast cancer case more difficult to manage. Therefore, individually-tailored therapies have been the subject of many studies for these patients. The purpose of this study was to determine clinicopathological features of young breast cancer patients in Bali from 2014-2016.

This was a descriptive study of young breast cancer patients ( $\leq 40$ years) in Bali from January 2014 until June 2016. The samples were taken from the Perhimpunan Ahli Bedah Onkologi Indonesia cancer registry in Sanglah General Hospital Bali. There were 90 samples gathered from the cancer registry, and 56 samples (62.2\%) had complete clinicopathological records. Clinicopathological features included in this study were age group, histopathological type, primary tumor size, regional lymph node involvement, presence of distant metastasis, stage regrouping, tumor grade, hormonal receptor status, Her2 overexpression status, and breast cancer subtype.

Among 56 young breast cancer patients, the mean age was $33.86 \pm 4.193$ years old. The youngest patient was 22 years old, and the majority of the samples were in the 31-35 years age group (26 samples, 46.4\%). Only 2 samples $(3.6 \%)$ had special type carcinoma, both of them were invasive lobular carcinoma, and the rest of the samples were invasive carcinoma of no special type. The 2 samples with invasive lobular carcinoma were in 31-35 years age group, had stage II (T2NOMO) and III (T4N1MO) breast cancer, both with grade II tumor and Luminal A subtype. The majority of primary tumor size was T4 (30 samples, $53.6 \%$ ), nodal status was N1 (29 samples, $51.8 \%)$, and only 10 samples $(17.9 \%)$ had distant metastasis. On stage regrouping, the majority of patients was in stage III (35 samples, $62.5 \%$ ) and had grade III tumor (33 samples, 58.9\%). There were 10 samples (17.9\%) with Luminal A subtype, 19 samples (33.9\%) with Luminal B subtype, 16 samples (28.6\%) with Her2 type subtype, and 11 samples (19.6\%) with triple negative breast cancer subtype.

We concluded that the majority of young breast cancer patients in Bali have invasive carcinoma of no special type in advanced stage, with high grade tumor, and Luminal B subtype.

Keywords: young age breast cancer, clinicopathological features. 